\title{
Leaching as a pretreatment process to complement torrefaction in improving co-firing characteristics of Jatropha curcas seed cake
}

Buddhike Neminda Madanayake ${ }^{\mathrm{a}}$, Suyin Gan ${ }^{\mathrm{a},{ }^{*}}$, Carol Eastwick ${ }^{\mathrm{b}}$, Hoon Kiat $\mathrm{Ng}^{\mathrm{c}}$

${ }^{a}$ Department of Chemical and Environmental Engineering, The University of Nottingham Malaysia Campus, Jalan Broga, 43500 Semenyih, Selangor Darul Ehsan, Malaysia.

${ }^{\mathrm{b}}$ Energy and Sustainability Research Division, Faculty of Engineering, The University of Nottingham, University Park, Nottingham NG7 2RD, UK.

${ }^{\mathrm{c}}$ Department of Mechanical, Materials and Manufacturing Engineering, The University of Nottingham Malaysia Campus, Jalan Broga, 43500 Semenyih, Selangor Darul Ehsan, Malaysia.

*Corresponding author. Tel. +603 8924 8162; fax. +603 8924 8017. E-mail address:

suyin.gan@nottingham.edu.my (S. Gan)

\begin{abstract}
The presence of certain inorganic elements in biomass causes issues such as slagging, fouling and corrosion when co-firing with coal for power generation. In this work, the efficacy of leaching to remove these elements from Jatropha curcas seed cake was investigated. Leaching of both untorrefied and torrefied seed cakes was carried out in Milli-Q water at temperatures of $20^{\circ} \mathrm{C}, 35^{\circ} \mathrm{C}$ and $50^{\circ} \mathrm{C}$. At $20^{\circ} \mathrm{C}$, the two critical elements, potassium and chlorine, decreased by as much as $85 \%$ and $97 \%$, respectively. Leaching at higher temperatures was only beneficial for the more intensely-torrefied biomass, since they were more resistant to leaching. The electrical
\end{abstract}


conductivity and ion content of the leachates were measured, as were the inorganic elemental content, dry ash content, volatile matter content and higher heating value (HHV) of the solid seed cake. A secondary benefit of the leaching was an increase in the HHV by up to $10 \%$.

\section{Keywords}

Leaching, biomass, Jatropha curcas, coal co-firing

\section{Introduction}

Biomass co-firing has the potential to become a key contributor to the global energy mix in the future. It allows the non-renewability and carbon-neutrality of biomass to be exploited to an extent while utilising existing coal power plants. However, the combustion of biomass has its own set of drawbacks which are a result of the different thermophysical and chemical properties of biomass compared with coal. Pretreatment processes such as torrefaction and leaching which could curtail these issues are hence an important avenue of research. Torrefaction is the mild pyrolysis of biomass at a temperature of $200^{\circ} \mathrm{C}-300^{\circ} \mathrm{C}$ in an inert atmosphere to improve fuel characteristics such as the higher heating value and energy density. The aim of leaching - the focus of this study - is to reduce the typically high inorganic content of biomass, which is one of the main concerns associated with biomass combustion. Alkali and alkaline earth metals result in the formation of deposit-forming compounds, which cause a host of problems during combustion. These include slagging in grate-fired combustors, fouling of heat transfer surfaces and bed agglomeration in fluidised bed combustors. Potassium (K) and calcium (Ca) are two key metals of concern [1-4]. In addition to this, biomass may contain chlorine $(\mathrm{Cl})$ and sulphur $(\mathrm{S})$ which results in the formation of acidic products which lead to accelerated corrosion of metal 
surfaces within the combustion system [5]. Together, the presence of these inorganic elements has a negative impact on combustion efficiency, plant reliability and maintenance costs; plant performance and overall operating costs suffer [7].

Leaching studies have been conducted on a number of different types of raw biomass with the primary aim of reducing the inorganic content. Different approaches to leaching such as spraying, flushing and soaking have been compared by a few studies $[8,9]$. However, most laboratory-based investigations employ soaking, i.e. submerging the biomass in water for a specific period of time [3,10-15]. This method is favoured in laboratory-scale studies since it is simple to implement and allows variables such as the leaching time and/or water temperature to be controlled and hence their effect on the leaching efficacy investigated. The soaking method also allows leachate samples to be collected at regular intervals and analysed, hence facilitating the monitoring of the progress of the leaching process with time $[9,16,17]$. For these reasons, the present study's leaching technique is also based on soaking, with a shaking water bath used to control the temperature and standardise mixing. Since the properties and behaviour of biomass can vary widely, standardising leaching techniques and limits of the parameters (such as the liquid:solid ratio, particle size and soaking time) poses difficulties. Hence when considering an as-yet-unstudied type of biomass, an initial laboratory-based study such as this would provide an invaluable overview of its leaching characteristics; these results would provide a baseline for future studies which are more finely tuned to the biomass in question.

The biomass used in this study is derived from Jatropha curcas seeds which are gaining recognition as viable feedstock for biodiesel production. It is drought-resistant and its toxicity prevents competition with the food industry $[18,19]$. Since the oil yield from the seeds is only about $18 \%$ by mass of the dry fruit, there is the possibility of using the resultant waste seed cake 
as a substitute for coal in combustion systems [21]. Although the efficacy of torrefaction and leaching as independent pre-treatments on biomass has been investigated before, there is a dearth of information on the combined effects of both processes on any particular biomass. The purpose of this study is to explore the use of leaching as a pre-treatment process to reduce the inorganic content of Jatropha seed cake, and hence compliment torrefaction in mitigating the potential problems arising when it is cofired with coal for power generation. To this effect, the leaching of both untorrefied and torrefied Jatropha seed cake was investigated. To the best knowledge of the authors, this is the first study of its kind on Jatropha seed cake.

\section{Material and methods}

\subsection{Materials}

Jatropha curcas seeds provided by ACGT Sdn. Bhd. (Malaysia) were extracted for oil at an external facility. The oil yield was $12 \%$. The resulting solid residue (seed cake) consisted of two distinct components - hard, dark, rod-like structures ("type A") in a soft, oily, loose soil-like matrix ("type B"). The type B was approximately $3 / 4$ by weight of the total seed cake, and hence was the primary subject of the study. Samples of type B were torrefied in a horizontal tube furnace under an inert (nitrogen) atmosphere at temperatures of $200^{\circ} \mathrm{C}, 250^{\circ} \mathrm{C}$ and $300^{\circ} \mathrm{C}$ for a period of 30 min each ("LT", "MT" and "HT", respectively). Triplicate torrefaction runs were carried out at each temperature. The type A seed cake was not torrefied, but was milled and sieved to two particle size fractions $-<1 \mathrm{~mm}$ ("fine" particle size) and 1-2.36 mm ("medium" particle size).

\subsection{Leaching experimental matrix}

The major leaching study involved the type B seed cake. Two factors were varied, the leaching temperature of the water and the torrefaction state. The full-factorial matrix used is 
shown in Table 1. For the type A seed cake, only untorrefied samples were leached at a temperature of $35^{\circ} \mathrm{C}$ and the variation was in the particle size fraction. All runs were triplicated. A control run with no biomass added was also incorporated for each leaching temperature.

\subsection{Leaching methodology}

The leaching process was carried out for $24 \mathrm{~h}$ in a Jeiotech BS-21 water bath. $3.0 \mathrm{~g}$ of each biomass sample was submerged in $300 \mathrm{ml}$ of Milli-Q water in a glass jar. EC readings were taken every hour for the first $6 \mathrm{~h}$, and the last $3 \mathrm{~h}$ of the 24-h period. At the end of the 24-h period, leachate samples $(10 \mathrm{ml})$ were extracted from each jar using a syringe and the solid separated out by decanting and filtration. The solid was dried in a vacuum oven at $60^{\circ} \mathrm{C}$ under a gauge vacuum of $900 \mathrm{mbar}$ for $4 \mathrm{~h}$.

\subsection{Analytical methods}

Thermogravimetric analysis (TGA) and X-ray fluorescence (XRF) spectrometry were carried out on each solid sample to determine their proximate composition and inorganic elemental content, respectively. The TGA was carried out in a TA Instruments Q500, using a heating profile based on the conditions outlined in British Standards publications concerning the proximate analysis of biomass (British Standards BS EN 14774-2:2009, BS EN 15148:2009, BS EN 14775:2009). A Bruker S8 Tiger instrument was used for the XRF spectrometry. A bomb calorimeter (IKA C5000) was used to measure the higher heating value (HHV) of selected samples. Inductively coupled plasma mass spectroscopy (ICP-MS) and ion chromatography (IC) were carried out on the leachate samples to measure the cation and anion levels present, respectively. ICP-MS was performed on a Thermo iCAP Q while a Thermo Dionex ICS-1000 was used for IC. A 1-in-10 dilution was carried out on the leachate samples using $2 \%$ nitric acid and Milli-Q water for the ICP-MS and IC, respectively. 


\section{Results and discussion}

\subsection{Electrical conductivity (EC)}

Fig. 1 shows the variation of the EC during the course of leaching of type B seed cake. Since EC of a solution is a function of the concentration of ions in it and can be measured instantly using an EC meter, it provides a useful method of monitoring the progress of the leaching process with time. The mean EC for the final $3 \mathrm{~h}$ are approximately constant. Thus, it can be assumed that by this time, the leaching process is complete.

The final EC of the HT runs are the lowest, followed by that of the MT runs. There is a degree of overlap between the LT and UT runs. The observed trends indicate that increasing the torrefaction intensity makes the biomass more resistant to the leaching process. This is also reflected in the initial leaching rates (curve gradient). The lowest rate is in the HT samples, followed by the MT samples. Again, there is some overlap between the LT and UT samples.

There is a general increase in the leaching rate as well as the final EC at higher leaching temperatures. However, the effect of the temperature appears to be highly dependent on the torrefaction state. The separation of the respective curves is significantly greater for the HT and MT samples. Increasing the leaching temperature is thus much more effective in increasing the leachability of the more intensely torrefied samples, which are also the most resistant to the leaching process.

\subsection{Ion analysis of leachate}

Fig. 2 shows the final concentration (net value calculated using the control run) of the major cations and anions present in the leachate as measured by ICP-MS and IC, respectively. The ions in question are $\mathrm{K}, \mathrm{Cl}$, magnesium $(\mathrm{Mg})$ and phosphate $\left(\mathrm{PO}_{4}\right)$. The net $\mathrm{EC}$ of the solution is 
superimposed; this value is the difference between the EC after $24 \mathrm{~h}$ and the initial EC. Although not exact, a correlation can be observed as expected between the total ion concentration and the EC. The extent of removal of the individual elements indicated by the net ion concentration cannot be directly compared with the elemental content of the solid leached biomass (from XRF spectroscopy; Section 3.3), as the elemental content of the solid is represented as a \% by weight while the leachate ion concentration shows a measurement in absolute terms.

From Fig. 2(a), a clear positive trend can be observed in the effect of the leaching temperature on the $\mathrm{K}$ levels in the type B leachate. When the leaching temperature is increased from $20^{\circ} \mathrm{C}$ to $50^{\circ} \mathrm{C}$, the $\mathrm{K}$ levels in the UT and LT samples increase by $10.2 \%$ and $15.1 \%$, respectively. For the MT sample, the increase is a more substantial 33.6\%. However, for the HT sample, the increase is $164.3 \%$, i.e. more than doubled. Thus, increasing the leaching temperature has a more substantial effect with the more intensely-torrefied samples. Also, the ion content leached out (in absolute terms) decreases as the torrefaction temperature is increased. From Fig. 2(b), it can be seen that the larger particle size results in lower EC and ion concentration in the type A leachate. This can be explained by the smaller surface area-tovolume ratio of the larger particles. The final EC and $\mathrm{K}$ content of the leachate drops by $12.4 \%$ and $6.9 \%$, respectively, when the larger particle size is used. Since the most prominent ion present in the leachate by a significant margin is $\mathrm{K}$, the trends observed in the total ion levels are comparable to those of $\mathrm{K}$; this is true of both type A and type B.

\subsection{XRF spectroscopy}

Table 2 and Fig. 3 show the elemental inorganic composition of the solid biomass. These are the mean levels of the most abundant inorganic elements measured using XRF spectroscopy $-\mathrm{K}$, $\mathrm{Ca}, \mathrm{Mg}, \mathrm{Cl}, \mathrm{S}$ and phosphorous $(\mathrm{P})$. The sum of the values of these elements is shown next to 
each column on the chart. The dry ash content obtained from TGA has been superimposed on the graph as well to illustrate the expected correlation between the inorganic content and the ash content. Fig. 4 show the main effects plots and interaction plots (whichever is relevant) for the XRF data generated by Minitab for type B. Table 3 shows the p-values obtained from the analysis of variance (ANOVA) carried out by the software. Throughout the Minitab analysis, the variable "LeachState" shows the leaching temperature in degrees Celsius or "UL" if unleached, while "TorrState" refers to the temperature in degrees Celsius at which the sample has been torrefied (all at $30 \mathrm{~min}$ holding time) or "UT" if untorrefied. To analyse the effect of the leaching temperature more closely, the statistical analysis was repeated with the data for the unleached samples omitted.

Sections 3.3.1 to 3.3.3 analyse the results pertaining to the type B seed cake.

\subsection{1. $\mathrm{K}$ and $\mathrm{Cl}$}

$\mathrm{K}$ and $\mathrm{Cl}$ have been considered in previous studies to be the critical inorganic elements which are responsible for ash deposit formation and corrosion [22-25]. Of the inorganic elements investigated, $\mathrm{K}$ and $\mathrm{Cl}$ show the most significant decrease following leaching.

Looking at the interaction plots for $\mathrm{K}$ and $\mathrm{Cl}$, it can be seen that for the torrefied and mildly torrefied (LT) seed cake, there is no appreciable effect of using higher leaching temperatures. For the MT seed cake, a linear drop of the $\mathrm{K}$ level is observed as the water temperature is increased. For the HT seed cake, the drop is only observed after $35^{\circ} \mathrm{C}$. This indicates that as far as $\mathrm{K}$ and $\mathrm{Cl}$ are concerned, a higher torrefaction temperature increases the resistance of the biomass to leaching, and consequently, a higher leaching temperature is required. In the HT samples, the K content decreases by only $0.09 \mathrm{wt} \%$ when the temperature is increased from $20^{\circ} \mathrm{C}$ to $35^{\circ} \mathrm{C}$, and by a further $0.86 \mathrm{wt} \%$ when increased to $50^{\circ} \mathrm{C}$. This trend indicates that at this degree of 
torrefaction, a much higher water temperature $\left(>50^{\circ} \mathrm{C}\right)$ would be required to cause any appreciable leaching. Very high water temperatures have negative practical implications such as controlling evaporation and a higher energy expenditure to maintain the temperature for extended periods of time.

$\mathrm{K}$ is the dominant inorganic component of Jatropha seed cake, and hence its reduction is a vital outcome of the leaching process. At $20^{\circ} \mathrm{C}$, the $\mathrm{K}$ and $\mathrm{Cl}$ content of the untorrefied type $\mathrm{B}$ Jatropha biomass decreased by $85 \%$ (to $<1 \mathrm{wt} \%$ ) and $97 \%$ (to approximately $0.02 \mathrm{wt} \%$ ), respectively. In comparison, the $\mathrm{K}$ and $\mathrm{Cl}$ range of typical coals is $0.01-0.09 \mathrm{wt} \%$ and $0.01-0.03$ $\mathrm{wt} \%$, respectively [26]. The leaching process is hence effective in bringing down the levels of these crucial inorganic elements in the untorrefied biomass closer to those of coal.

The relative ease of leaching of $\mathrm{K}$ and $\mathrm{Cl}$ from the untorrefied Jatropha is consistent with results from leaching studies conducted on other types of biomass - wheat straw [13], rice straw $[9,12,13]$, olive-derived biomass [3], grassland herbage [27], switchgrass [15]. The extent to which these elements are removed by leaching is related to the mode in which they occur in the structure of the biomass. $\mathrm{K}$ is typically found as $\mathrm{K}^{+}$ions which are either dissolved in water present in the plant tissue or organically bound [28]. $\mathrm{Cl}$ is found as free $\mathrm{Cl}^{-}$ions or as part of organic compounds [13]. The high water-leachability of $\mathrm{K}$ and $\mathrm{Cl}$ from the untorrefied Jatropha suggests that these elements are present as simple ions which readily dissolve in water. The decrease in their extraction as the torrefaction intensity is increased indicates that the structural changes occurring in the biomass during the torrefaction process has an effect on the mode of occurrence of $\mathrm{K}$ and $\mathrm{Cl}$ within the biomass structure, causing the free ions to be bound more rigidly to the organic compounds. It follows that a higher energy input would be required to 
break these bonds, hence the enhancement of the leachability of the torrefied biomass that was observed at higher water temperatures.

\subsection{2. $M g$ and $P$}

From interaction plots for $\mathrm{Mg}$ and $\mathrm{P}$, it can be seen that the UT and mildly torrefied (LT) seed cake undergo a decrease in the levels of these elements following the leaching process; the $\mathrm{Mg}$ content undergoes a slight increase and the $\mathrm{P}$ content remains approximately unchanged in the highly-torrefied (MT and HT) biomass. The irregularities in the Mg content can be attributed to inhomogeneity and measurement uncertainty introduced by the instrument, compounded by the very low levels detected (less than $0.6 \mathrm{wt} \%$ ).

While the measured P content does not exceed $2.5 \mathrm{wt} \%$, the levels fall to $<0.25 \mathrm{wt} \%$ and $<1$ $\mathrm{wt} \%$ in the untorrefied and LT samples, respectively; there is no appreciable effect of increasing the leaching water temperature. $\mathrm{P}$ in biomass can occur as soluble phosphate salts or as $\mathrm{P}$ containing organic molecules [28]. The results suggest that they occur as the former in the untreated Jatropha seed cake, but undergoes a transformation to the latter during the torrefaction process. Since even the high-temperature leaching (which was effective in the case of the K content) did not reduce the $\mathrm{P}$ content of the torrefied biomass, it appears that the $\mathrm{P}$ atoms become more rigidly bonded to the organic molecules than the $\mathrm{K}$ atoms. Due to the fact that $\mathrm{P}$ can occur in both water-soluble and water-insoluble forms in biomass, there is a wide range of $\mathrm{P}$ leachability that is reported in the literature, from as much as $>50 \%$ [29] to non-detectable [30] and even slightly increased levels [8].

\subsubsection{Ca and $S$}

Since the interaction between torrefaction state and leaching is statistically insignificant for $\mathrm{Ca}$ and $\mathrm{S}$ (interaction $\mathrm{p}>0.05$ ), the main effects plots are considered here. The Ca levels show a clear increase following leaching. The $\mathrm{S}$ levels show an increase as well, although the trend is 
more irregular in this case. The low main effects $p$-values $(p<0.05)$ also reflect this. Since the leaching process cannot increase the levels of any element, the conclusion derived from these observations is that there is a very high degree of inhomogeneity in the Ca and S levels (more so than the other major inorganic elements) throughout the type B seed cake. The problem is aggravated by the fact that the measured quantities of these elements are relatively low (less than $1.5 \%)$, which increases the uncertainty of the measurement.

\subsubsection{Effect of particle size}

Comparing the two categories of type A as illustrated in Fig. 3(b), the effect of particle size can be determined; the smaller particles undergo a decrease of $80 \%$ compared to the $77 \%$ reduction in the larger particle size. Although the magnitude of the difference is not substantial, this would be the expected direction of change since the larger particle size would have less overall surface area exposed to the water for the same mass of seed cake. The inorganic composition of the two leached type A size fractions appear to be similar. Type B sees a decrease by an even smaller $71 \%$ after leaching at $35^{\circ} \mathrm{C}$. A possible explanation for this is that the oil content of the type B seed cake interferes with the mechanism by which the ions leave the structure of the biomass.

From the p-values in Table 3, it can be seen that there is a significant interaction between the factors for all elements except $\mathrm{Cl}$, i.e. the different types of seed cake respond differently to the leaching, with respect to the levels of these elements. The nature of this variation can be seen by examining the interaction plots in Fig. 5. $\mathrm{K}, \mathrm{Mg}, \mathrm{P}$ and $\mathrm{Cl}$ see falling levels during leaching, in all three types of seed cake. The type A (fine) undergoes a greater decrease in the $\mathrm{K}, \mathrm{Mg}$ and $\mathrm{P}$ content compared to the type A (medium). All 3 types of seed cake show a similar response to leaching where $\mathrm{Cl}$ is concerned. Irregular trends are observed in the $\mathrm{Ca}$ and $\mathrm{S}$ content (with the 
Ca content even appearing to increase) and these are attributed to the inhomogeneity in the biomass and uncertainty of the instrument when measuring small quantities, as in the $\mathrm{Ca}$ and $\mathrm{S}$ results for the type B biomass.

\subsection{Dry ash free volatile matter (DAF VM) content and higher heating value (HHV)}

Fig. 6(a) show the main effects plot and the interaction plot for the DAF VM content of type B. The p-value for the interaction is 0.032 ; looking at the interaction plot, it can be seen that there is a marked difference between the behaviour of the UT and torrefied seed cake. The torrefied samples all show irregular behaviour, while the UT case shows an appreciable decrease in the DAF VM. The leaching process would be expected to remove some of volatiles from the seed cake, which is what is observed in the UT samples. However, torrefaction (even mildly) appears to reduce the leachability of the volatiles. A possible explanation is that the light volatiles that are driven off in the torrefaction process are the ones that are more readily soluble in water and are hence removed from the UT biomass during leaching. The volatiles that are left following torrefaction process are heavier and are either insoluble in water or adsorbed onto the structure of the biomass, and are thus impervious to the leaching process.

The relationship between the DAF VM content and the higher heating value (HHV) has been demonstrated in literature. A decreasing DAF VM content corresponds to an increasing DAF fixed carbon (FC) content as the volatiles lost contain less carbon (C) atoms than hydrogen (H) and oxygen $(\mathrm{O})$ atoms. This leads to a reduction in the $\mathrm{H} / \mathrm{C}$ and $\mathrm{O} / \mathrm{C}$ ratios, and since $\mathrm{C}-\mathrm{H}$ and $\mathrm{C}-$ O bond energies are weaker than those of $\mathrm{C}-\mathrm{C}$, the calorific value increases [31, 32]. This 
relationship is reflected in the factorial plots for the HHV of the leached samples, shown in Fig. 6(b). A p-value of 0.004 indicates a statistically significant interaction and this is illustrated in the interaction plot by the non-parallel lines. The highly-torrefied seed cake shows an irregular trend, while the UT case shows a clear increase in the HHV after the sample is leached. As explained earlier, this agrees with the trends observed in the DAF VM content. The mean HHV increases from 24.06 MJ/kg to $25.32 \mathrm{MJ} / \mathrm{kg}$ (by $5 \%$ ) and $26.47 \mathrm{MJ} / \mathrm{kg}$ (by $10 \%$ ) after leaching at $20^{\circ} \mathrm{C}$ and $50^{\circ} \mathrm{C}$, respectively.

The increase in the HHV that was observed was not one of the primary aims behind leaching; instead, torrefaction is the pretreatment process that aims to enhance the HHV. However, the mild increase in HHV following leaching is a welcome secondary benefit, since a higher HHV is a desirable characteristic for a biofuel. Enhancement of the HHV following leaching has been reported previously as well $[12,30]$.

Although the higher HHV following leaching is advantageous, it should be noted that it is at the cost of the total energy content of the biomass, as some organic content is being lost via the leachate. Quantification of the relative energy loss is beyond the scope of this study, but is suggested as an area for future investigations. Relative energy losses ranging from $1 \%$ to $28 \%$ have been reported in the literature, with increasing leaching temperature having a detrimental effect on the loss value [13].

\section{Conclusions}

The $\mathrm{K}$ and $\mathrm{Cl}$ content of both type A and type $\mathrm{B}$ seed cake (from XRF) show the most unambiguous reductions following leaching, with those of type B decreasing by $85 \%$ and $97 \%$, 
respectively (at $\left.20^{\circ} \mathrm{C}\right)$. More intensely-torrefied samples are more resistant to leaching, and higher leaching temperatures are required to overcome this. EC and ion analysis of the leachate corroborates the XRF data. A secondary benefit of the leaching is a mild increase in the HHV.

\section{Acknowledgements}

This work was supported by the Faculty of Engineering, University of Nottingham (UK and Malaysia) under the Engineering InterCampus PhD Scholarship. The authors would also like to thank ACGT Sdn Bhd (Malaysia) and Dr. Cheah Suan Choo for providing the Jatropha curcas seeds.

\section{References}

1. $\quad$ Baxter, L.L., Miles, T.R., Jenkins, B.M., Milne, T., Dayton, D., Bryers, R.W., Oden, L.L.: The behavior of inorganic material in biomass-fired power boilers: field and laboratory experiences. Fuel Process. Technol. 54, 47-78 (1998).

2. Turn, S., Kinoshita, C., Ishimura, D.: Removal of inorganic constituents of biomass feedstocks by mechanical dewatering and leaching. Biomass and Bioenergy. (1997).

3. Vamvuka, D., Zografos, D., Alevizos, G.: Control methods for mitigating biomass ashrelated problems in fluidized beds. Bioresour. Technol. 99, 3534-44 (2008).

4. Werther, J., Saenger, M., Hartge, E.-U., Ogada, T., Siagi, Z.: Combustion of agricultural residues. Prog. Energy Combust. Sci. 26, 1-27 (2000).

5. Dayton, D., Jenkins, B., Turn, S.: Release of inorganic constituents from leached biomass during thermal conversion. Energy \& Fuels. 1977, 860-870 (1999).

6. Nielsen, H., Frandsen, F.: The implications of chlorine-associated corrosion on the operation of biomass-fired boilers. Prog. Energy Combust. Sci. 26, 283-298 (2000). 
7. Kargbo, F., Xing, J., Zhang, Y.: Pretreatment for energy use of rice straw: A review. African J. Agric. Res. 4, 1560-1565 (2009).

8. Carrillo, M. a., Staggenborg, S. a., Pineda, J. a.: Washing sorghum biomass with water to improve its quality for combustion. Fuel. 116, 427-431 (2014).

9. Jenkins, B., Bakker, R., Wei, J.: On the properties of washed straw. Biomass and Bioenergy. I, 177-200 (1995).

10. Lam, P.Y., Lim, C.J., Sokhansanj, S., Lam, P.S., Stephen, J.D., Pribowo, A., Mabee, W.E.: Leaching characteristics of inorganic constituents from oil palm residues by water. Ind. Eng. Chem. Res. 53, 11822-11827 (2014).

11. Chin, K.L., H’ng, P.S., Paridah, M.T., Szymona, K., Maminski, M., Lee, S.H., Lum, W.C., Nurliyana, M.Y., Chow, M.J., Go, W.Z.: Reducing ash related operation problems of fast growing timber species and oil palm biomass for combustion applications using leaching techniques. Energy. 1-9 (2015).

12. Yu, C., Thy, P., Wang, L., Anderson, S.N., VanderGheynst, J.S., Upadhyaya, S.K., Jenkins, B.M.: Influence of leaching pretreatment on fuel properties of biomass. Fuel Process. Technol. 128, 43-53 (2014).

13. Deng, L., Zhang, T., Che, D.: Effect of water washing on fuel properties, pyrolysis and combustion characteristics, and ash fusibility of biomass. Fuel Process. Technol. 106, 712-720 (2013).

14. Davidsson, K., Korsgren, J., Pettersson, J., Jäglid, U.: The effects of fuel washing techniques on alkali release from biomass. Fuel. 81, 137-142 (2002).

15. Ravichandran, P., Gibb, D., Corscadden, K.: Controlled Batch Leaching Conditions for Optimal Upgrading of Agricultural Biomass. J. Sustain. Bioenergy Syst. 03, 186-193 (2013).

16. Jensen, P. a., Sander, B., Dam-Johansen, K.: Removal of $\mathrm{K}$ and $\mathrm{Cl}$ by leaching of straw char. Biomass and Bioenergy. 20, 447-457 (2001).

17. Ho, Y.S., Harouna-Oumarou, H.A., Fauduet, H., Porte, C.: Kinetics and model building of leaching of water-soluble compounds of Tilia sapwood. Sep. Purif. Technol. 45, 169-173 (2005).

18. Gübitz, G., Mittelbach, M., Trabi, M.: Exploitation of the tropical oil seed plant Jatropha curcas L. Bioresour. Technol. 67, 73-82 (1999).

19. Wever, D.-A.Z., Heeres, H.J., Broekhuis, A. a.: Characterization of Physic nut (Jatropha curcas L.) shells. Biomass and Bioenergy. 37, 177-187 (2012). 
20. Sricharoenchaikul, V., Atong, D.: Thermal decomposition study on Jatropha curcas L. waste using TGA and fixed bed reactor. J. Anal. Appl. Pyrolysis. 85, 155-162 (2009).

21. Singh, R.N., Vyas, D.K., Srivastava, N.S.L., Narra, M.: SPRERI experience on holistic approach to utilize all parts of Jatropha curcas fruit for energy. Renew. Energy. 33, 18681873 (2008).

22. Hansen, L., Nielsen, H.: Influence of deposit formation on corrosion at a straw-fired boiler. Fuel Process. Technol. 189-209 (2000).

23. Sander, B.: Properties of Danish biofuels and the requirements for power production. Biomass and Bioenergy. 12, 177-183 (1997).

24. Wieck-Hansen, K., Overgaard, P., Larsen, O.: Cofiring coal and straw in a $150 \mathrm{MW}$ e power boiler experiences. Biomass and Bioenergy. 19, 395-409 (2000).

25. Yin, C., Rosendahl, L. a., Kær, S.K.: Grate-firing of biomass for heat and power production. Prog. Energy Combust. Sci. 34, 725-754 (2008).

26. Oleschko, H., Schimrosczyk, a, Lippert, H., Muller, M.: Influence of coal composition on the release of Na-, $\mathrm{K}-, \mathrm{Cl}-$, and S-species during the combustion of brown coal. Fuel. 86, 2275-2282 (2007).

27. Tonn, B., Dengler, V., Thumm, U., Piepho, H.-P., Claupein, W.: Influence of leaching on the chemical composition of grassland biomass for combustion. Grass Forage Sci. 66, 464-473 (2011).

28. Zevenhoven, M., Yrjas, P., Skrifvars, B.-J., Hupa, M.: Characterization of Ash-Forming Matter in Various Solid Fuels by Selective Leaching and Its Implications for FluidizedBed Combustion. Energy \& Fuels. 26, 6366-6386 (2012).

29. Zhang, S., Dong, Q., Zhang, L., Xiong, Y., Liu, X., Zhu, S.: Effects of water washing and torrefaction pretreatments on rice husk pyrolysis by microwave heating. Bioresour. Technol. 193, 442-448 (2015).

30. Said, N., Bishara, T., García-Maraver, a., Zamorano, M.: Effect of water washing on the thermal behavior of rice straw. Waste Manag. 33, 2250-2256 (2013).

31. McKendry, P.: Energy production from biomass (Part 1): Overview of biomass. Bioresour. Technol. 83, 37-46 (2002).

32. Narvaez, I., Orio, A.: Biomass gasification with air in an atmospheric bubbling fluidized bed. Effect of six operational variables on the quality of the produced raw gas. Ind. Eng. Chem. Res. 5885, 2110-2120 (1996). 


\section{Tables}

Table 1: Experimental matrix

\begin{tabular}{|c|c|c|c|c|c|}
\hline & & & Tol & tate & \\
\hline & & UT & LT & MT & HT \\
\hline Leaching & 20 & $\mathrm{x}$ & $\mathrm{x}$ & $\mathrm{x}$ & $\mathrm{x}$ \\
\hline temperature & 30 & $\mathrm{x}$ & $\mathrm{x}$ & $\mathrm{x}$ & $\mathrm{x}$ \\
\hline$\left({ }^{0} \mathrm{C}\right)$ & 50 & $\mathrm{X}$ & $\mathrm{x}$ & $\mathrm{x}$ & $\mathrm{X}$ \\
\hline
\end{tabular}

UT: untorrefied; LT, MT, HT have been torrefied for $30 \mathrm{~min}$ at $200^{\circ} \mathrm{C}, 250^{\circ} \mathrm{C}, 300^{\circ} \mathrm{C}$, respectively. 
Table 2: Most abundant inorganic elements (from XRF spectroscopy) of unleached biomass (all values given in \% weight).

Element

\begin{tabular}{|c|c|c|c|c|c|c|}
\hline & UT & LT & MT & HT & fine particle size & $\begin{array}{c}\text { medium particle } \\
\text { size }\end{array}$ \\
\hline $\mathbf{K}$ & 5.82 & 6.60 & 7.49 & 9.32 & 6.64 & 5.56 \\
\hline $\mathbf{C a}$ & 0.86 & 0.92 & 1.00 & 1.17 & 0.93 & 0.85 \\
\hline Mg & 0.3 & 0.36 & 0.38 & 0.48 & 0.39 & 0.33 \\
\hline $\mathbf{P}$ & 1.45 & 1.59 & 1.70 & 2.01 & 1.36 & 1.18 \\
\hline $\mathbf{C l}$ & 0.78 & 0.92 & 1.06 & 1.35 & 0.78 & 0.79 \\
\hline $\mathbf{S}$ & 0.53 & 0.43 & 0.26 & 0.15 & 0.57 & 0.54 \\
\hline
\end{tabular}


Table 3: p-values from ANOVA of XRF data.

Type B (unleached and leached)

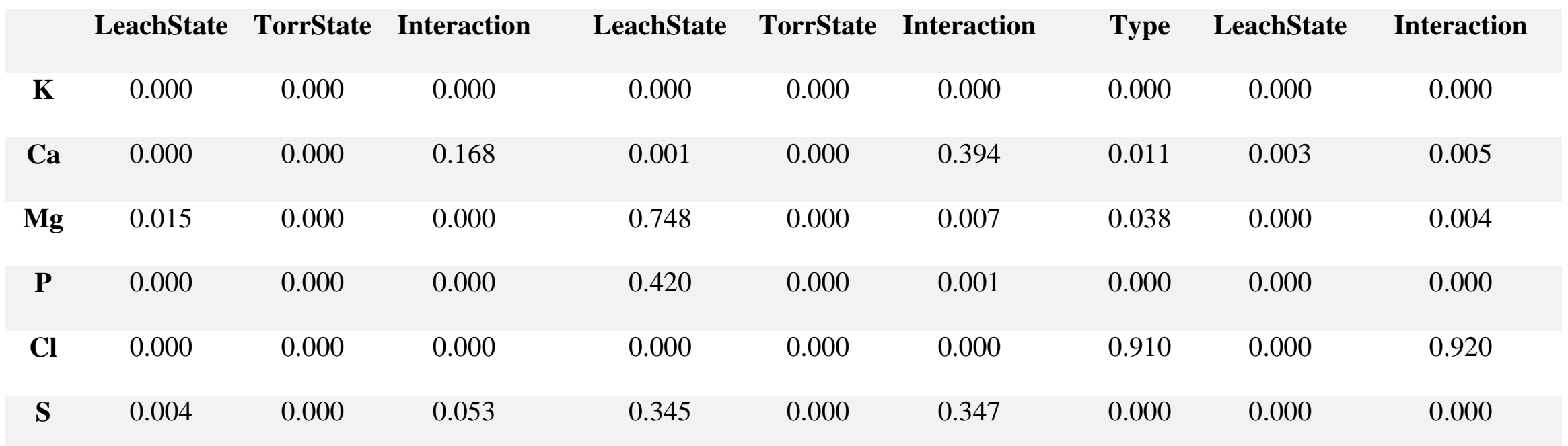




\section{Figures}

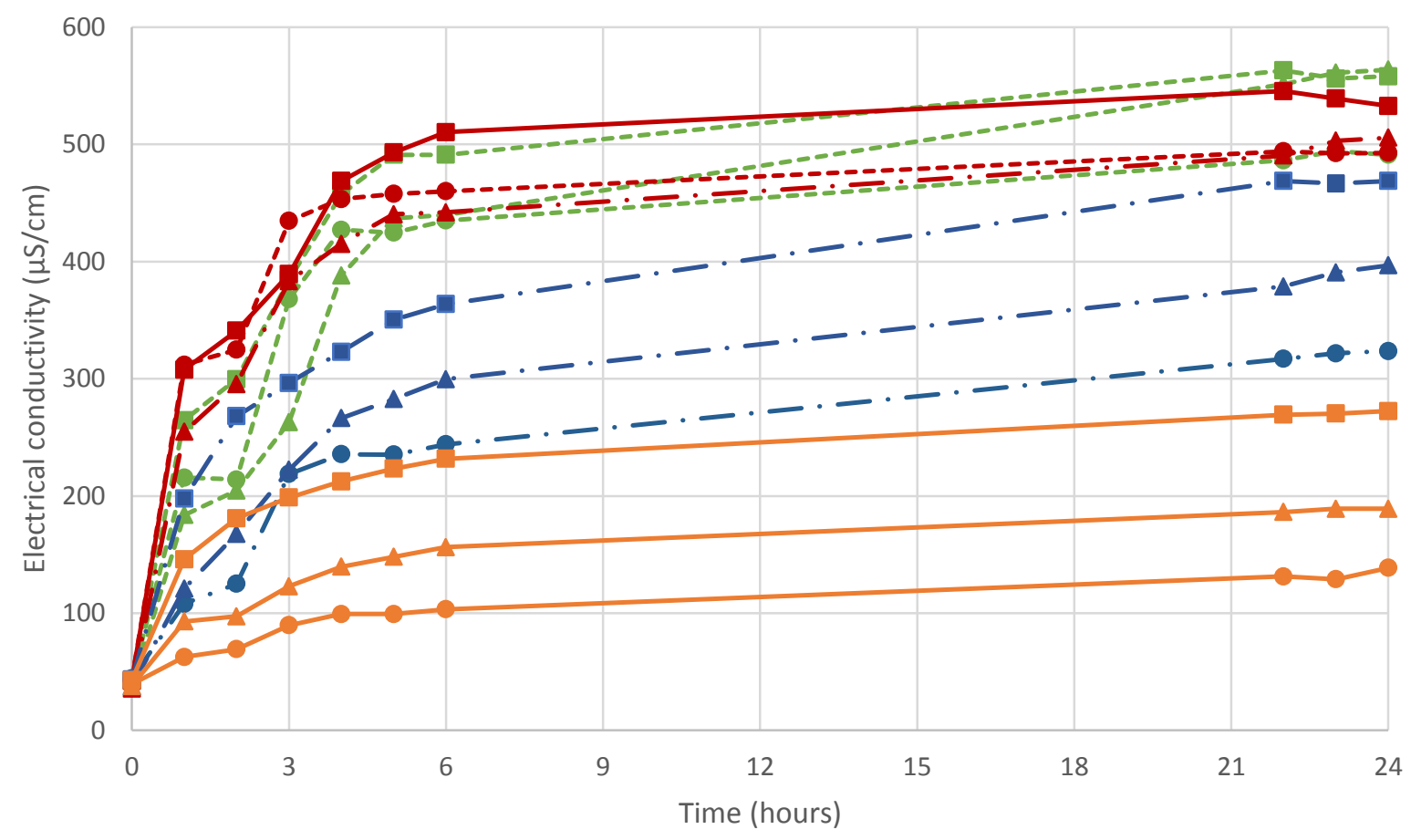

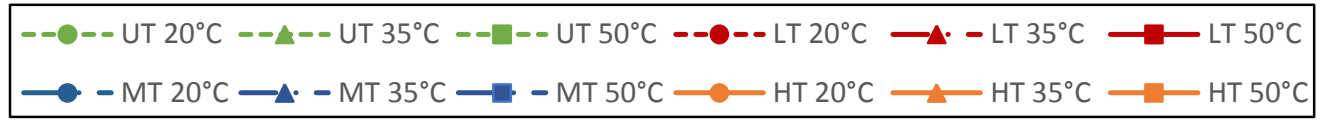

Fig. 1. Progression of mean EC with time. 


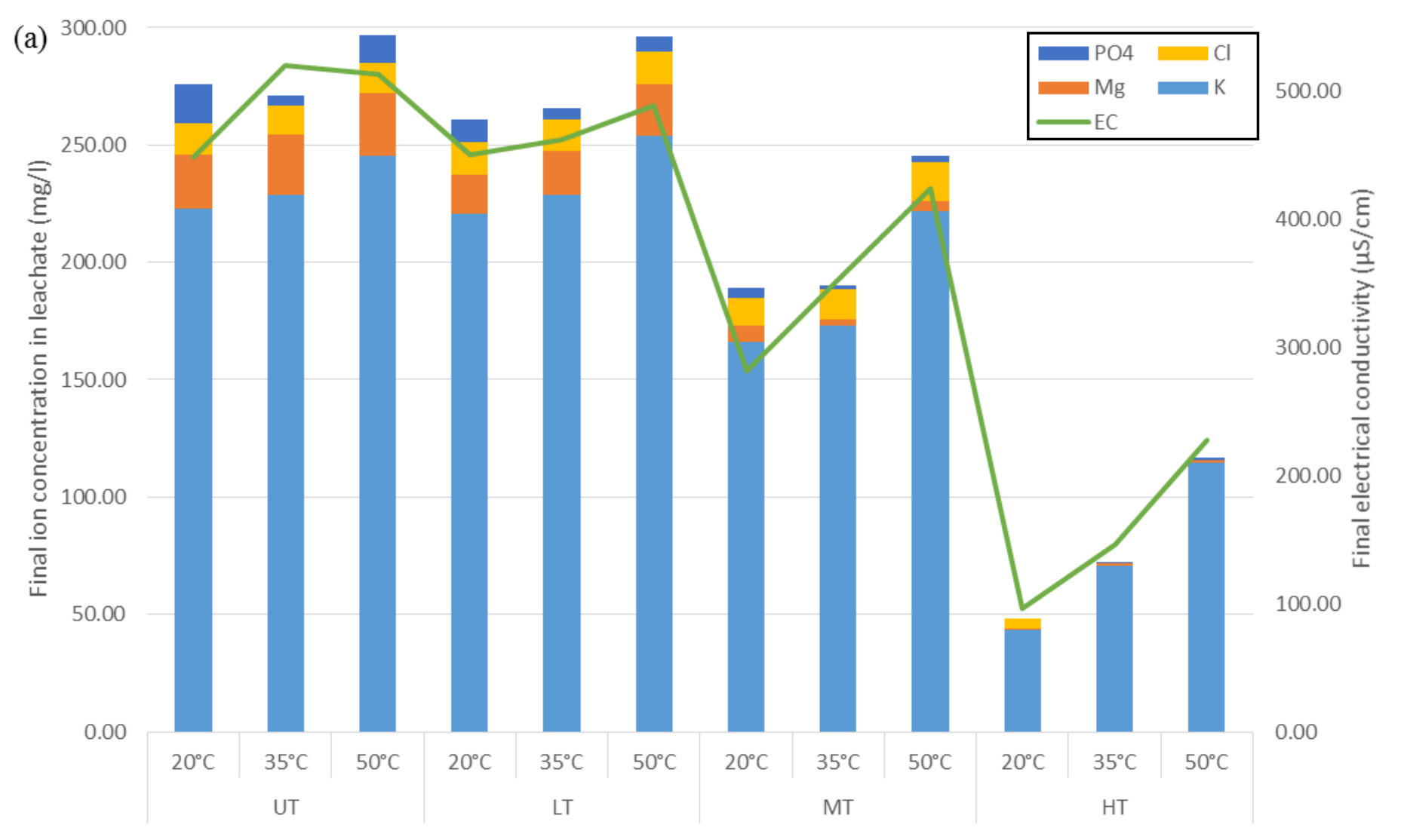

(b)

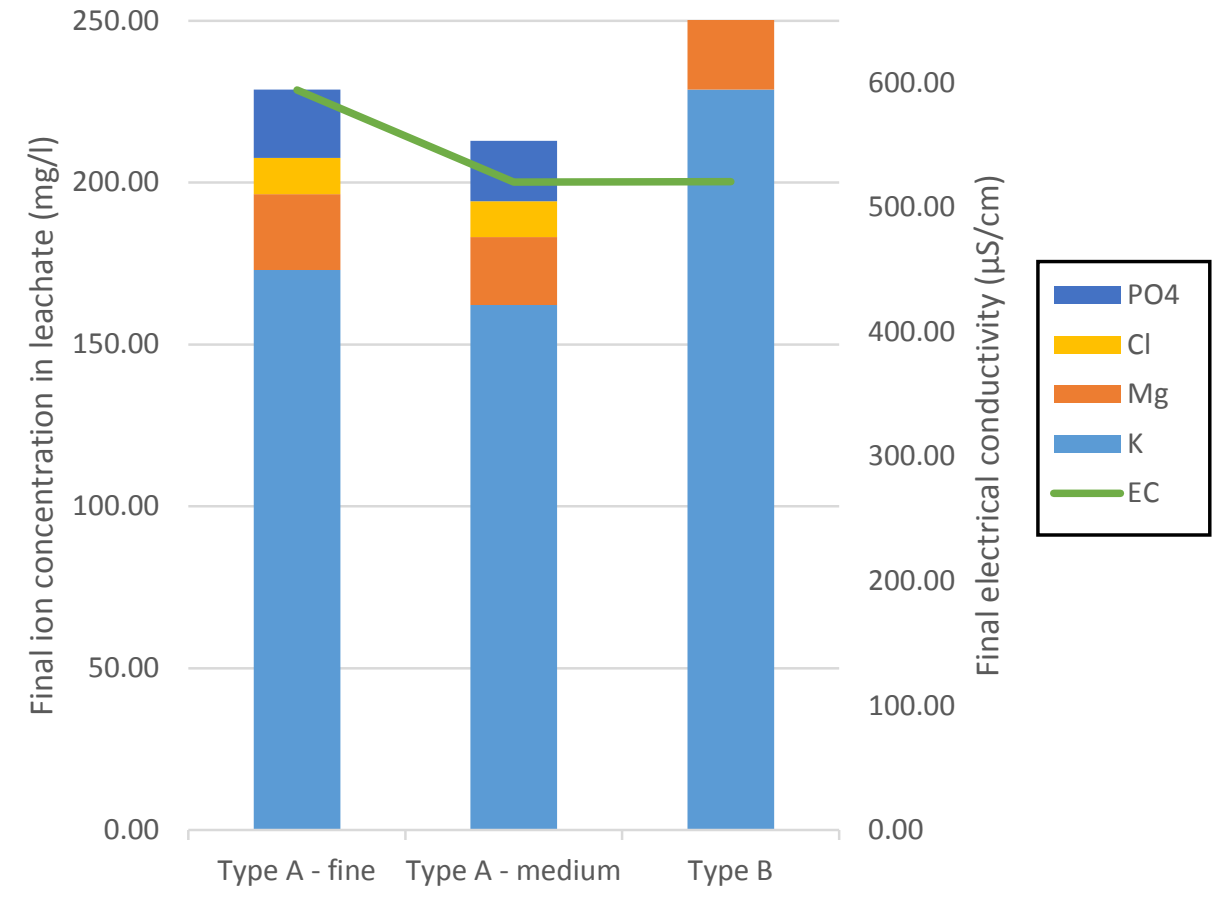

Fig. 2. Net ion concentration and EC after $24 \mathrm{~h}$ for (a) type B and (b) type A 


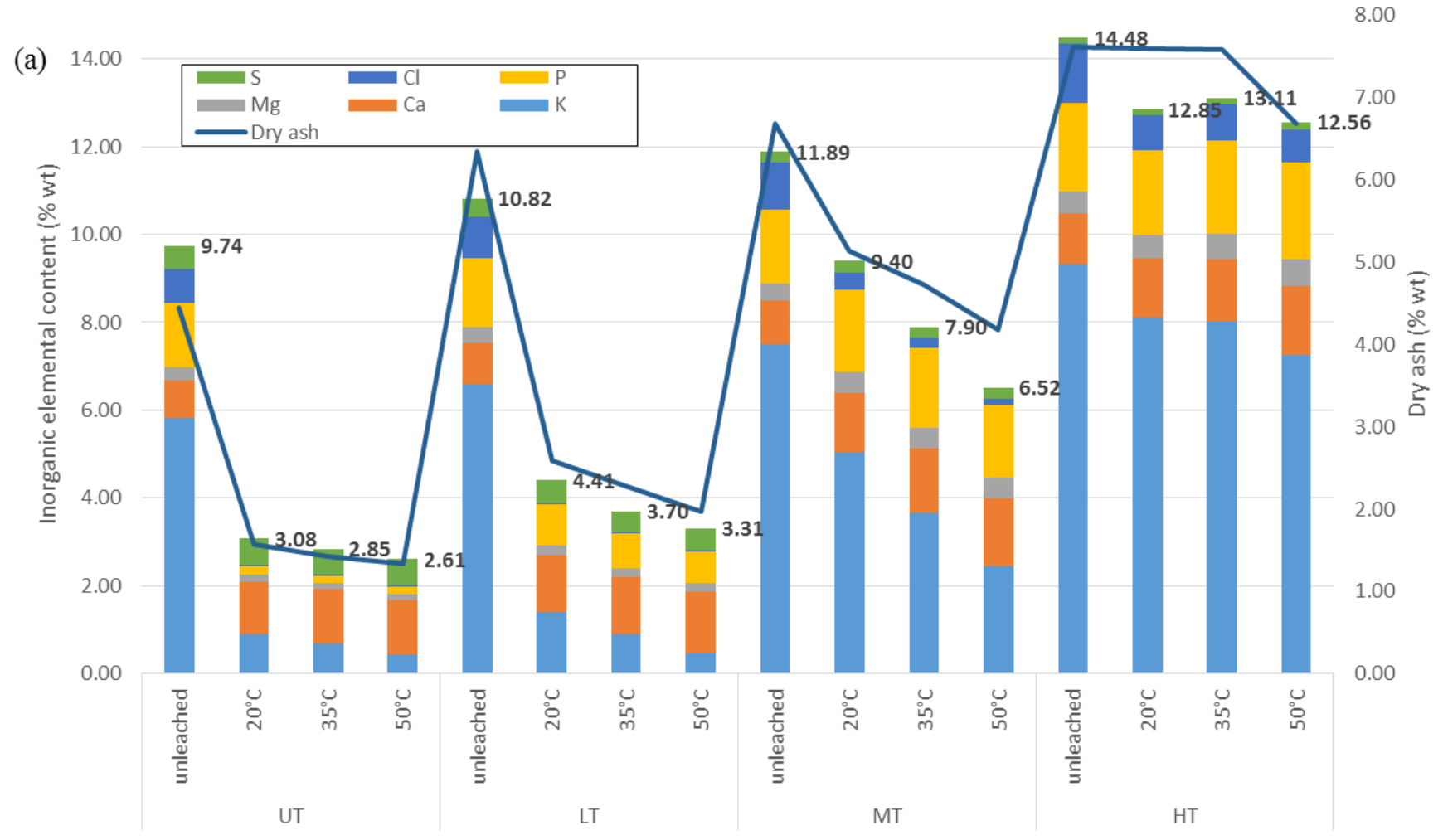

(b)

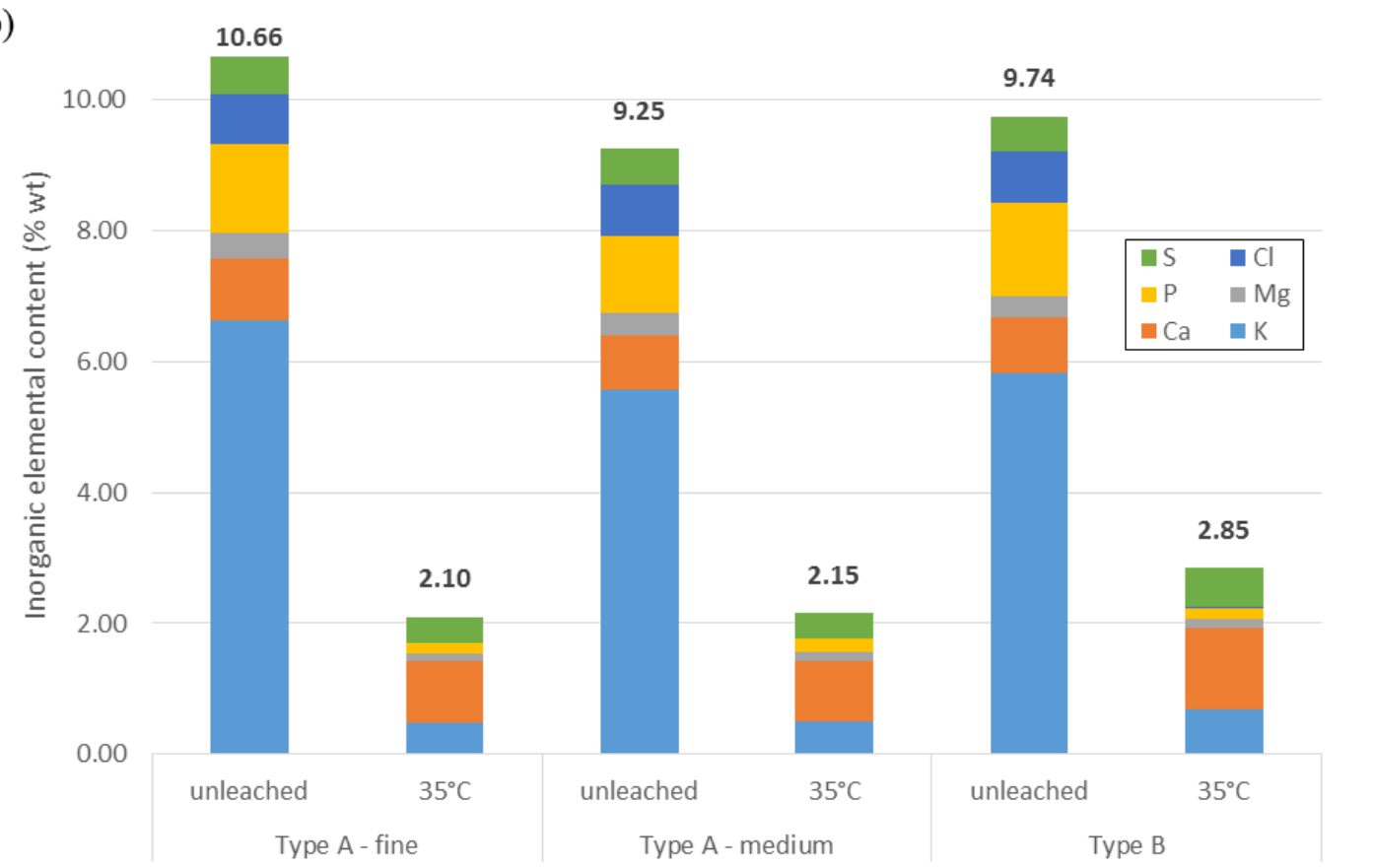

Fig. 3. Total inorganic content from XRF for leached and unleached (a) untorrefied and torrefiedtype B and (b) untorrefied type A and type B. 

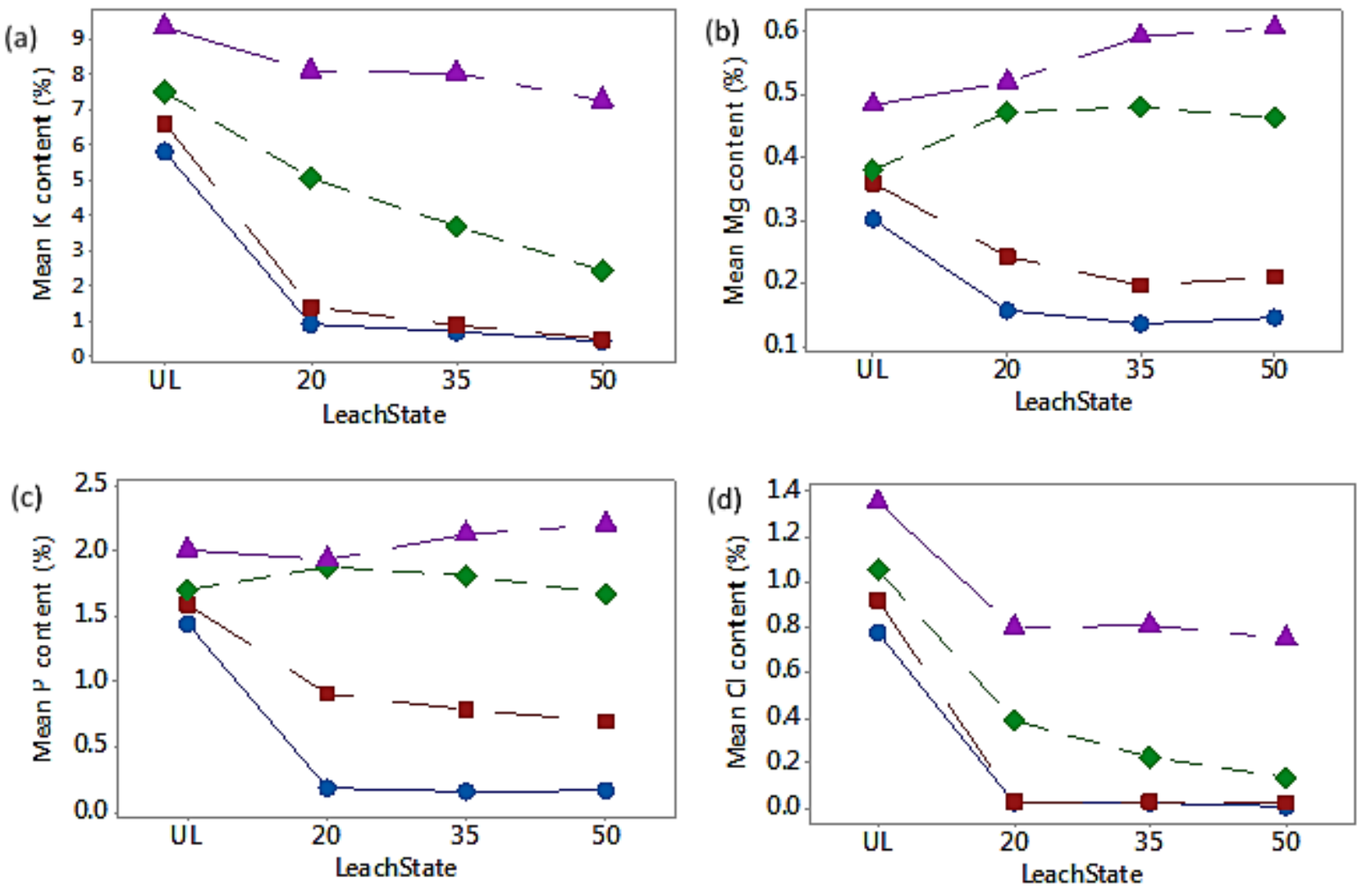

TorrState

UT $\longrightarrow 200 \longrightarrow-250 \longrightarrow 300$
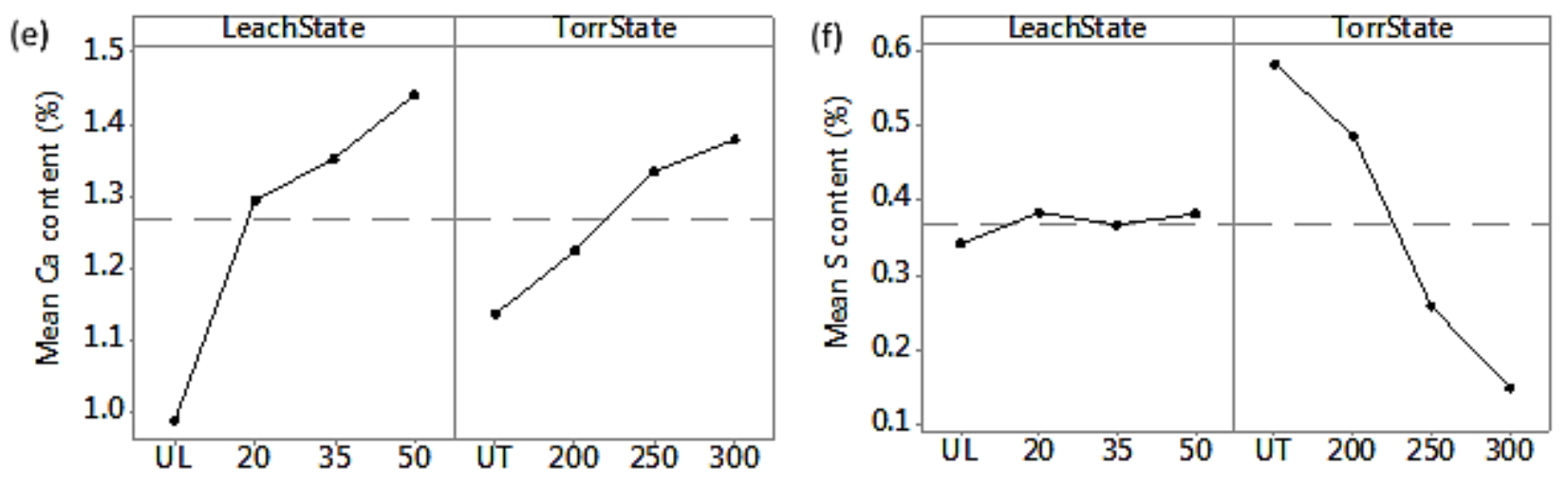

Fig. 4. Factorial plots for XRF content of type B (a) K interaction, (b) Mg interaction, (c) P interaction, (d) $\mathrm{Cl}$ interaction, (e) Ca main effects and (f) $\mathrm{S}$ main effects. 

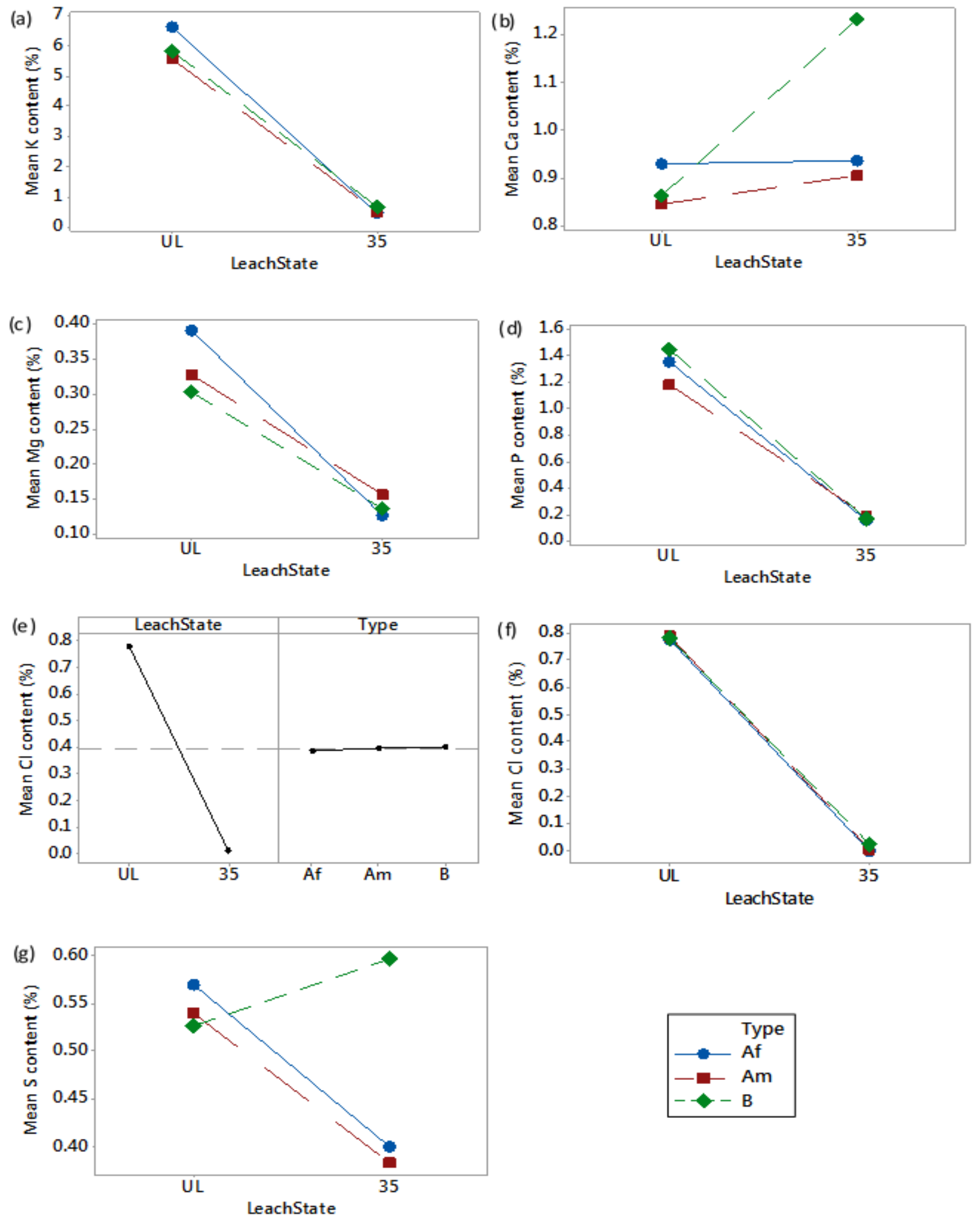

Fig. 5. Factorial plots for XRF content of type A (a) $\mathrm{K}$ interaction, (b) Ca interaction, (c) $\mathrm{Mg}$ interaction, (d) P interaction, (e) $\mathrm{Cl}$ main effects, (f) $\mathrm{Cl}$ interaction and (g) $\mathrm{S}$ interaction. 

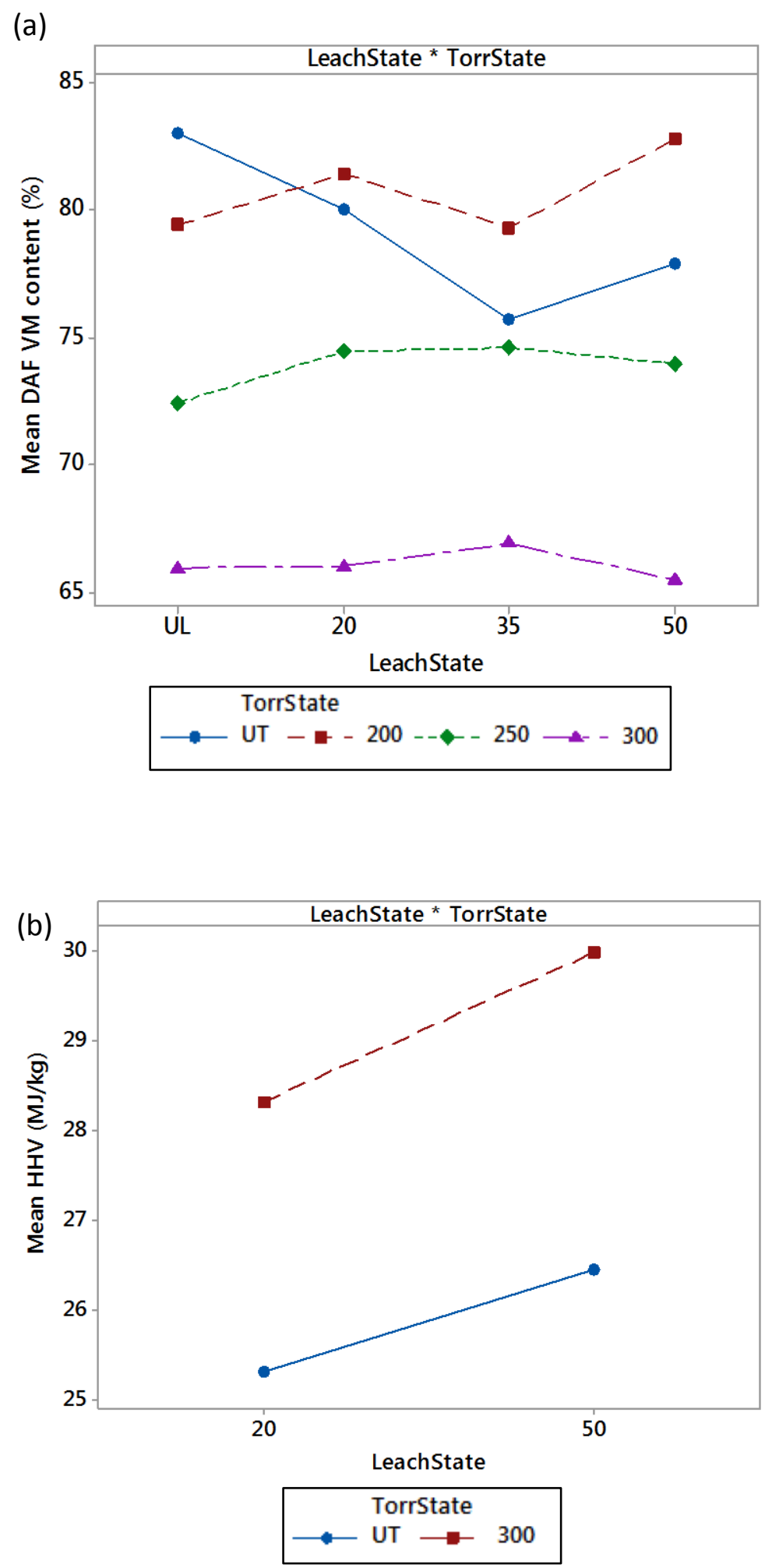

Fig. 6. Interaction plots for type B (a) DAF VM content and (b) HHV. 